\title{
Pearls \& Oy-sters: Windmill nystagmus in paraneoplastic cerebellar degeneration
}

Sun-Uk Lee, MD, Hyo-Jung Kim, PhD, Sea-Won Oh, BSc, Eun Young Song, MD, PhD, Jeong-Yoon Choi, MD, PhD, and Ji-Soo Kim, MD, PhD

Neurology ${ }^{\circledR}$ 2018;91:e1831-e1833. doi:10.1212/WNL.0000000000006477

\section{Pearls}

- Windmill nystagmus is characterized by alternating changes in the direction of horizontal and vertical nystagmus, which results in clockwise or counterclockwise rotation of the beating direction of spontaneous nystagmus.

- Typical and variant forms of windmill nystagmus are mostly observed in patients with a visual loss.

- Windmill nystagmus may be a sign of paraneoplastic cerebellar degeneration (PCD) in the absence of visual loss.

\section{Oy-sters}

- Subacute progressive ataxia is the typical presentation of PCD.

- Downward corrective saccades after horizontal head impulse tests (HITs), downbeat head-shaking nystagmus, and positional downbeat nystagmus indicate dysfunction of the vestibulocerebellum, and may be observed in PCD.

\section{Case report}

A 61-year-old man with 15 pack-years of smoking presented with gait difficulty for 3 weeks. The patient had intractable nausea, vomiting, and unsteadiness that made him unable to walk unaided. Examination showed alternating horizontal spontaneous nystagmus with intervening vertical components that also alternated its directions (figure, A; video 1 ). Direction-changing gaze-evoked nystagmus was observed during lateral gazes. Downbeat nystagmus was induced by horizontal head shaking and positional maneuvers including straight-head hanging and DixHallpike maneuver to either side. Saccades were normal, but smooth pursuit was impaired bilaterally. Bedside HITs showed decreased and abnormal upward (perverted) responses of the horizontal vestibulo-ocular reflex that were indicated by oblique downward catch-up saccades in either direction (video 2). His gait was ataxic, but without appendicular ataxia or dysdiadochokinesia. Results of bithermal caloric tests, subjective visual vertical, and pure-tone audiometry were normal. Brain MRIs and magnetic resonance angiography were also normal. CSF study showed pleocytosis of $13 / \mathrm{mm}^{3}$ (lymphocyte $91 \%$ ), protein of $86.9 \mathrm{mg} / \mathrm{dL}$, and glucose of $60 \mathrm{mg} / \mathrm{dL}$ (serum glucose at $96 \mathrm{mg} / \mathrm{dL}$ ). CSF cytology was negative for atypical cells. Workups for hidden malignancy were performed with a suspicion of PCD, and chest CT disclosed a $2.9 \mathrm{~cm}$ enhancing mass in the right interlobar station (figure, B). FDG-PET revealed increased glucose uptake in the interlobar areas that was indicative of lymph node metastasis (figure, C). Small cell lung carcinoma (SCLC) was confirmed with transbronchial needle aspiration. The serum was positive for anti-SOX1 and anti-Hu antibodies, but negative for other paraneoplastic antibodies including anti-Ri, Ma2, CV2/CRMP5, amphiphysin, recoverin, and titin. IV methylprednisolone $(1 \mathrm{~g} / \mathrm{d})$ and immunoglobulin $(0.4 \mathrm{mg} / \mathrm{kg} / \mathrm{d})$ for 5 consecutive days were ineffective. One month after initiation of combined chemotherapy and radiotherapy, however, he became able to walk on his own with resolution of the spontaneous alternating nystagmus and abnormal HITs.
Correspondence

Dr. J.-S. Kim

jisookim@snu.ac.kr

MORE ONLINE

- Videos

\footnotetext{
From the Departments of Neurology (S.-U.L., J.-Y.C., J.-S.K.) and Laboratory Medicine (E.Y.S.), Seoul National University College of Medicine; Dizziness Center, Clinical Neuroscience Center, and Department of Neurology (S.-U.L., H.-J.K., S.-W.O., J.-Y.C., J.-S.K.), and Research Administration Team (H.-J.K.), Seoul National University Bundang Hospital, Seongnam; and Department of Laboratory Medicine (E.Y.S.), Seoul National University Hospital, South Korea.

Go to Neurology.org/N for full disclosures. Funding information and disclosures deemed relevant by the authors, if any, are provided at the end of the article.
} 


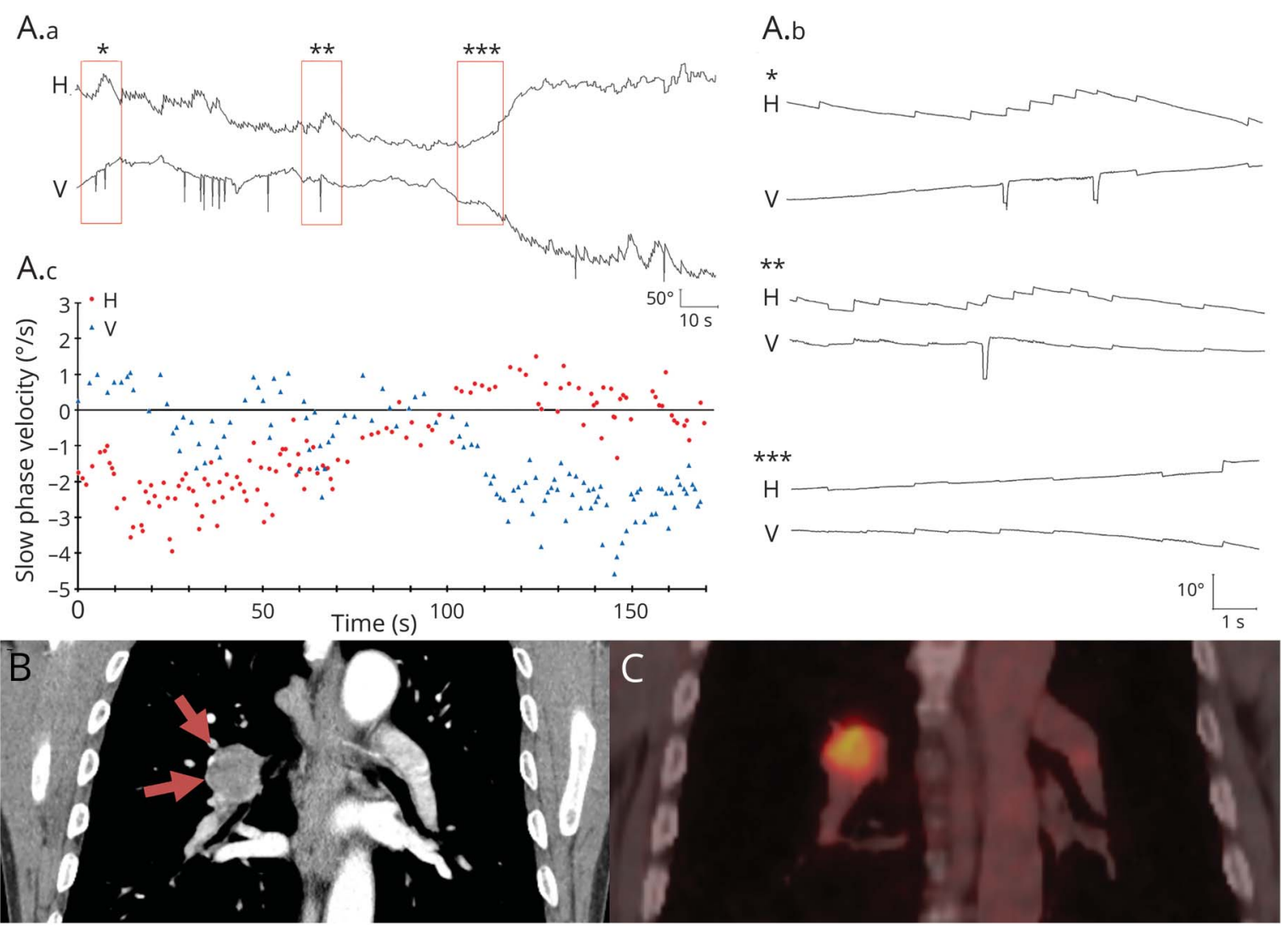

(A.a) Video-oculographic recording (SLMED, Seoul, South Korea) of the horizontal (H) and vertical (V) position of the left eye shows spontaneous nystagmus alternating its direction in each horizontal and vertical plane. (A.b) The magnified view of the spontaneous nystagmus is presented according to each portion selected in red boxes on the recording of spontaneous nystagmus, right-downbeating $(*)$, right-upbeating $(* \star)$, and left-upbeating (***). In these figures, upward deflection of the graphs indicates rightward or upward eye motion, while downward deflection indicates leftward or downward eye motion. (A.c) Plotting of the slow phase velocity of each spontaneous nystagmus recorded in the left upper column clearly shows sequential changes in the nystagmus direction both in the $\mathrm{H}$ and $\mathrm{V}$ directions. (B) Chest CT demonstrates a 2.9-cm enhancing mass in the right interlobar station (red arrows). (C) FDG-PET with CT fusion imaging documents increased glucose uptake in the same area, which is indicative of lymph node metastasis.

\section{Discussion}

Our patient with PCD showed various ocular motor findings that included windmill nystagmus, horizontal gaze-evoked nystagmus, downward catch-up saccades after horizontal HITs, downbeat nystagmus after horizontal head-shaking, and positional downbeat nystagmus.

Windmill nystagmus is characterized by alternating changes in the direction of horizontal and vertical nystagmus, which results in clockwise or counterclockwise rotation of the beating direction of spontaneous nystagmus. ${ }^{1}$ Variant forms of windmill nystagmus differ from the typical one by showing irregular duration or cycles of the nystagmus, or alternating diagonal nystagmus along the oblique axis. ${ }^{1}$ Windmill nystagmus is similar to periodic alternating nystagmus in that the nystagmus changes its direction in a certain order, but it occurs also in the vertical plane in windmill nystagmus. ${ }^{1}$ The mechanism of windmill nystagmus is explained by impaired visuo-vestibular interaction, which is necessary for calibration of eye position, since it was described in a patient with profound visual loss. ${ }^{1}$ However, windmill nystagmus observed in our patient with acquired cerebellar dysfunction but normal vision implicates that alternating horizontal and vertical nystagmus may occur without any visual deprivation. This is the first case of windmill nystagmus in association with acquired cerebellar dysfunction without a visual loss.

By convention, HITs are mostly normal in central lesions. However, abnormal upward deflection of the eyes during vestibular stimulation in the horizontal plane (cross-coupled responses), likewise downbeat nystagmus after horizontal head-shaking, can be observed in central vestibulopathies. This upward bias in eye motion may be ascribed to disinhibition and resultant hyperactivity of the anterior canal pathway due to floccular or nodular dysfunction. ${ }^{2,3}$ Our patient also showed positional downbeat nystagmus. When we assume a new head position, accurate estimation of the gravity direction relative to new head orientation is attained by the socalled tilt-estimator circuit that comprises the vestibulocerebellum and inferior brainstem. ${ }^{4,5}$ Thus, positional nystagmus may occur when the estimate of the gravity direction is erroneously biased away from true vertical due to vestibulocerebellar dysfunction. The gait and truncal ataxia without 
appendicular ataxia also indicates dysfunction of the midline cerebellar structures.

In our patient, the diagnosis of definite PCD could be made based on subacute and progressive cerebellar dysfunction and presence of anti-SOX1 and anti-Hu antibodies in association with SCLC. ${ }^{6}$ The SOX proteins are downregulated in the adult, and are expressed only in the Bergmann glia in the Purkinje cell layer of the cerebellum. ${ }^{7}$ SOX proteins are highly immunogenic when expressed in SCLC and give rise to various paraneoplastic syndromes such as Lambert-Eaton myasthenic syndrome, PCD, or limbic encephalitis. ${ }^{8}$ In contrast, anti- $\mathrm{Hu}$ antibody recognizes a family of RNA-binding proteins expressed in the nuclei of neurons and SCLC cells. ${ }^{9}$ The serum of our patient was positive for both anti-SOX and anti-Hu antibodies. Indeed, $31 \%$ of sera from paraneoplastic syndrome have more than 1 autoantibody. ${ }^{10}$ Furthermore, 37\% of sera having anti-SOX1 antibody are also positive for anti-Hu antibody, and $58 \%$ vice versa. ${ }^{8}$

This report extends the clinical features of PCD and causes of windmill nystagmus by highlighting this characteristic nystagmus in a patient with PCD in the absence of a visual loss.

\section{Author contributions}

Dr. Lee analyzed and interpreted the data and wrote the manuscript. Drs. H.J. Kim, Choi, Song, and Oh analyzed and interpreted the data and revised the manuscript. Dr. J.S. Kim designed and conceptualized the study, interpreted the data, and revised the manuscript.

\section{Study funding}

This study was supported by Basic Science Research Program through the National Research Foundation of Korea (NRF) funded by the Ministry of Education, Science and Technology (NRF-2016R1D1A1B04935568).

\section{Disclosure}

S. Lee, H. Kim, S. Oh, E. Song, and Y. Choi report no disclosures relevant to the manuscript. J. Kim serves as an associate editor of Frontiers in Neuro-otology and on the editorial boards of Journal of Clinical Neurology, Frontiers in Neuroophthalmology, Journal of Neuro-ophthalmology, Journal of Vestibular Research, Journal of Neurology, and Medicine. Go to Neurology.org/N for full disclosures.

\section{References}

1. Choi KD, Shin HK, Kim JS, et al. Variants of windmill nystagmus. J Neurol 2016;263: 1375-1381.

2. Walker MF, Zee DS. Cerebellar disease alters the axis of the high-acceleration vestibuloocular reflex. J Neurophysiol 2005;94:3417-3429.

3. Choi JY, Kim HJ, Kim JS. Recent advances in head impulse test findings in central vestibular disorders. Neurology 2018;90:602-612.

4. Choi JY, Kim JH, Kim HJ, Glasauer S, Kim JS. Central paroxysmal positional nystagmus: characteristics and possible mechanisms. Neurology 2015;84:2238-2246.

5. Choi JY, Glasauer S, Kim JH, Zee DS, Kim JS. Characteristics and mechanism of apogeotropic central positional nystagmus. Brain Epub 2018 Jan 24.

6. Graus F, Delattre J, Antoine J, et al. Recommended diagnostic criteria for paraneoplastic neurological syndromes. J Neurol Neurosurg Psychiatry 2004;75:1135-1140.

7. Graus F, Vincent A, Pozo-Rosich P, et al. Anti-glial nuclear antibody: marker of lung cancer-related paraneoplastic neurological syndromes. J Neuroimmunol 2005;165: 166-171.

8. Sabater L, Höftberger R, Boronat A, Saiz A, Dalmau J, Graus F. Antibody repertoire in paraneoplastic cerebellar degeneration and small cell lung cancer. PLoS One 2013;8:e60438.

9. Graus F, Keime-Guibert F, Reñe R, et al. Anti-Hu-associated paraneoplastic encephalomyelitis: analysis of 200 patients. Brain 2001;124:1138-1148.

10. Pittock SJ, Kryzer TJ, Lennon VA. Paraneoplastic antibodies coexist and predict cancer, not neurological syndrome. Ann Neurol 2004;56:715-719. 


\section{Neurology}

Pearls \& Oy-sters: Windmill nystagmus in paraneoplastic cerebellar degeneration

Sun-Uk Lee, Hyo-Jung Kim, Sea-Won Oh, et al.

Neurology 2018;91; $1831-\mathrm{e} 1833$

DOI 10.1212/WNL.0000000000006477

This information is current as of November 5, 2018

Updated Information \&

Services

References

Subspecialty Collections

Permissions \& Licensing

Reprints including high resolution figures, can be found at: http://n.neurology.org/content/91/19/e1831.full

This article cites 9 articles, 3 of which you can access for free at: http://n.neurology.org/content/91/19/e1831.full\#ref-list-1

This article, along with others on similar topics, appears in the following collection(s):

Nystagmus

http://n.neurology.org/cgi/collection/nystagmus

Paraneoplastic syndrome

http://n.neurology.org/cgi/collection/paraneoplastic_syndrome

Information about reproducing this article in parts (figures,tables) or in its entirety can be found online at:

http://www.neurology.org/about/about_the_journal\#permissions

Information about ordering reprints can be found online:

http://n.neurology.org/subscribers/advertise

Neurology ${ }^{\circledR}$ is the official journal of the American Academy of Neurology. Published continuously since 1951, it is now a weekly with 48 issues per year. Copyright () 2018 American Academy of Neurology. All rights reserved. Print ISSN: 0028-3878. Online ISSN: 1526-632X.

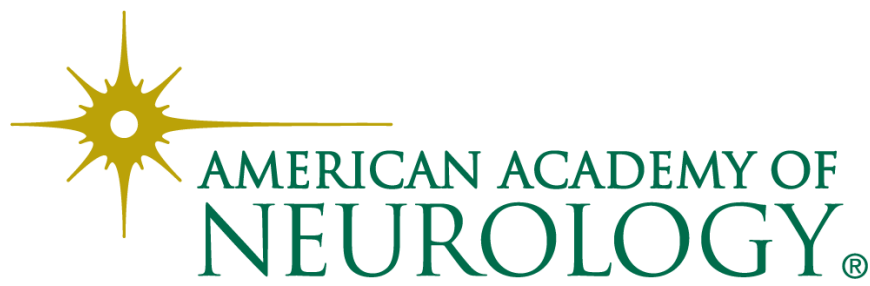

